\title{
EXTRAÇÃO E OXIDAÇÃO DO AMIDO DO MESOCARPO DE BABAÇU COM PERÓXIDO DE HIDROGÊNIO
}

\author{
M. R. A. SOUSA Jr. ${ }^{1}$, D. C. A. GOMES ${ }^{1}$, A. A. SANTANA ${ }^{2}$, W. F. de LA SALLES ${ }^{3}$ e A. P. \\ da COSTA FILHO ${ }^{3}$
}

${ }^{1}$ Bolsista de Iniciação Científica da UFMA, discente do curso de Engenharia Química

${ }^{2}$ Professor da Coordenação de Engenharia Química da UFMA

${ }^{3}$ Professor do Departamento de Tecnologia Química da UFMA E-mail para contato: mauroromeroasj@gmail.com

\begin{abstract}
RESUMO - O amido é um polímero natural de grande interesse industrial devido a sua abundância, ampla aplicabilidade e baixo custo. No entanto, seu uso na forma nativa é restrito, uma vez que possui limitações com relação às condições de processamento, fazendo-se necessário uma modificação de natureza física, química ou enzimática para adaptá-los às necessidades específicas. Diante disso, este trabalho tem como objetivo modificar quimicamente o amido contido no mesocarpo do babaçu, através de oxidação, a fim de inserir na cadeia do amido grupos carboxílicos. A farinha do mesocarpo e o amido extraído por tratamento com hidróxido de sódio foram caracterizados via testes de microscopia eletrônica de varredura acoplada a espectrometria de energia dispersiva (MEV/EDS), espectrofotometria na região do infravermelho com transformada de Fourier (FTIR) e composição química. $\mathrm{O}$ amido oxidado com peróxido de hidrogênio em meio ácido e básico foi analisado por EDS e FTIR. Os resultados mostraram que não houve grandes mudanças na composição química (aumento de 3,1\% na quantidade de amido extraído em relação à farinha pura) bem como na estrutura do amido oxidado em pH ácido ou básico. Além disso, observou-se uma pequena alteração nas ligações $\mathrm{C}-\mathrm{O}$ de ácidos carboxílicos para o meio básico, indicando que se faz necessário o estudo de novos métodos de extração e oxidação do amido de mesocarpo de babaçu.
\end{abstract}

\section{INTRODUÇÃO}

Atualmente, um dos grandes problemas ambientais que se tem conhecimento está relacionado aos plásticos derivados do petróleo, devido ao grande tempo necessário para a sua degradabilidade. Na tentativa de reverter esse quadro, tem-se utilizado amidos nativos modificados para formação de bioplásticos resistentes e com baixo tempo de degradação. Entretanto, sabe-se que os amidos nativos possuem limitações em relação às condições de processamento, sendo necessário modifica-los através de tratamentos físicos, químicos ou enzimáticos, proporcionando melhor proveito de suas propriedades funcionais e tecnológicas.

Dentre as fontes alternativas de amidos, encontra-se o babaçu, uma palmeira abundante no Maranhão e Piauí com elevado potencial de exploração sustentável. O mesocarpo, parte 
integrante do fruto, possui alto teor de amido, o que o torna uma matéria prima atrativa para a obtenção de um material modificado capaz de formar filmes biodegradáveis resistentes. Neste contexto, o objetivo principal deste trabalho foi oxidar o amido contido no mesocarpo do babaçu com peróxido de hidrogênio com o intuito de introduzir na estrutura do amido grupos carboxila, capazes de reticular e, posteriormente, formar biofilmes. Além disso, avaliaram-se as condições de oxidação em meio ácido e básico e a influência destes meios reacionais na composição e estrutura química do amido oxidado.

\section{EXPERIMENTAL}

\subsection{Material}

Farinha de mesocarpo de babaçu de nome comercial "Mesovital" (fabricada pela empresa União Cultural de Arari), proveniente de comércio local (São Luís, Maranhão) foi empregada como matéria prima. Esta farinha possui uma granulometria na faixa de 38 a 300 $\mu \mathrm{m}$ e diâmetro médio de partícula de $0,095 \mathrm{~mm}$.

\subsection{Métodos}

Extracão e caracterizaç̃o do amido contido no mesocarpo de babacu: Inicialmente, efetuou-se a moagem de $35 \mathrm{~g}$ da farinha durante 15 minutos em um moinho de bolas e realizou-se a classificação dos grãos por peneiramento (diâmetros iguais ou inferiores a $53 \mu \mathrm{m})$. Em seguida, a farinha foi dispersa em água destilada e posteriormente filtrada em um funil de Buchner. O resíduo sólido foi lavado três vezes com água destilada e uma vez com solução de $\mathrm{NaOH}$ 0,05M. Descartou-se o filtrado, e o produto sólido obtido foi transferido para uma placa de Petri para secagem em temperatura ambiente por 4 dias. Após a secagem, realizou-se novamente a moagem do material. $\mathrm{O}$ produto obtido foi caracterizado por FTIR, MEV/EDS e composição química em base úmida (IAL, 2008).

Oxidacão com peróxido de hidrogênio do amido extraído do mesocarpo de babacu e caracterização: Para oxidação do amido extraído do mesocarpo de babaçu, pesou-se $5 \mathrm{~g}$ de amido e dispersou-se essa massa em $30 \mathrm{ml}$ de água destilada. Adicionou-se o catalisador $\mathrm{FeSO}_{4} .7 \mathrm{H}_{2} \mathrm{O}(0,0015 \mathrm{~g})$ e o peróxido de hidrogênio $\left(\mathrm{H}_{2} \mathrm{O}_{2}\right)$ em intervalos regulares de 10 minutos. $\mathrm{O}$ sistema foi mantido a $40^{\circ} \mathrm{C}$ e em agitação contínua por $1 \mathrm{~h}$. $\mathrm{O} \mathrm{pH}$ foi regulado através da adição de $\mathrm{NaOH}(1 \mathrm{M})$ e $\mathrm{H}_{2} \mathrm{SO}_{4}$ (5\%). Após a reação, as amostras foram processadas conforme método adaptado de (Dias, 2001). O produto obtido foi disposto em placas de Petri e seco em temperatura ambiente por 4 dias. Após seco, foi caracterizado por FTIR e MEV.

\section{RESULTADOS E DISCUSSÃO}

\subsection{Caracterização da farinha pura e do amido extraído do mesocarpo do babaçu}

A Tabela 1 apresenta a composição centesimal (em base úmida) da farinha do mesocarpo do babaçu pura e após o processo de extração. Os valores observados para a farinha pura estão de acordo com a literatura (Silva, 2011). Entretanto, os valores para o 
amido após o processo de extração, apresentou um pequeno acréscimo em comparação com a amostra pura, o que indica possivelmente que houve uma ineficiência no processo de extração.

Tabela 1 - Caracterização química da farinha do mesocarpo do babaçu pura e após o processo de extração do amido

\begin{tabular}{|c|c|c|}
\hline Componente & $\begin{array}{c}\text { Amostra pura } \\
\left(\mathbf{g} / \mathbf{1 0 0 g}, \mathbf{b . u} .{ }^{*}\right)\end{array}$ & $\begin{array}{c}\text { Amostra após processo de extração } \\
(\mathbf{g} / \mathbf{1 0 0 g}, \mathbf{b . u .} * \boldsymbol{*})\end{array}$ \\
\hline Umidade & 10,4 & 15,2 \\
\hline Proteínas & 3,6 & 4,7 \\
\hline Lipídeos & 0,1 & 0,3 \\
\hline Cinzas & 0,9 & 1,4 \\
\hline Amido & 41,4 & 44,5 \\
\hline $\begin{array}{c}\text { Sacarídeos não } \\
\text { amiláceos }\end{array}$ & 43,6 & 33,9 \\
\hline *b.u = base úmida &
\end{tabular}

*b.u = base úmida

Em relação aos espectros de FTIR, a Figura 1 mostra os resultados obtidos para o amido extraído em relação à farinha pura do mesocarpo de babaçu.

Figura 1 - Espectrogramas na região do infravermelho da farinha pura e do amido extraído.

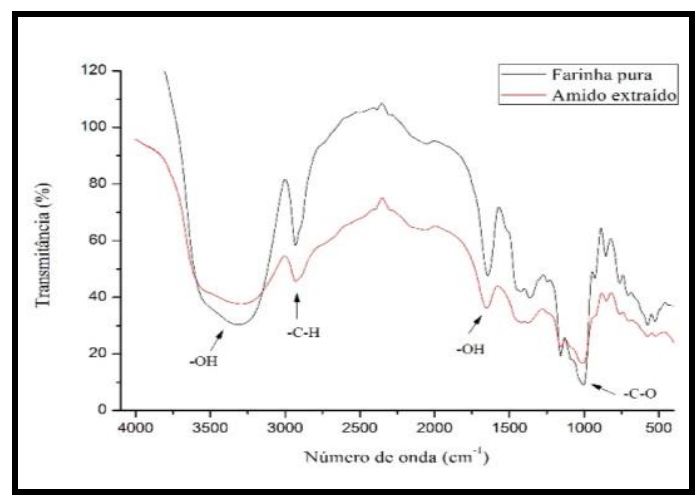

Observa-se um espectro característico de um material polimérico, com bandas largas e com sobreposição de frequências de vibração, devido à elevada massa molar das cadeias poliméricas. Com relação aos grupos funcionais, o espectro mostra uma banda larga na faixa de 3530 a $3200 \mathrm{~cm}^{-1}$ indicativa de deformação axial da ligação $-\mathrm{OH}$ dos monômeros de glicose. Em seguida, observa-se a ligação de estiramento de $\mathrm{C}-\mathrm{H}$ (dos grupos $\mathrm{CH}_{2}$ ) em número de onda de aproximadamente $2940 \mathrm{~cm}^{-1}$ e o grupo $-\mathrm{OH}$ proveniente da água de ligação $\left(\sim 1636 \mathrm{~cm}^{-1}\right)$. Observa-se uma vibração axial da ligação $\mathrm{C}-\mathrm{O}$ em aproximadamente $1000 \mathrm{~cm}^{-1}$ devido ao estiramento de grupos carboxílicos, evidenciando um certo grau de oxidação do amido. 
A Figura 2 mostra as imagens obtidas através de MEV da farinha pura e do amido extraído. Observa-se na imagem para a farinha pura (a) a presença de estruturas fibrosas, provavelmente devido a resíduos lignocelulósicos. Para o amido extraído (b), observa-se o rompimento de alguns grânulos em função do tratamento alcalino durante o processo de extração, disponibilizando o amido para a reação de oxidação. Também realizou-se análise complementar por EDS onde os resultados são apresentados na Tabela 2.

Figura 2 - Micrografias da farinha pura (a) e amido extraído (b) ampliadas 1500 vezes (aproximadamente $181 \mu \mathrm{m})$.

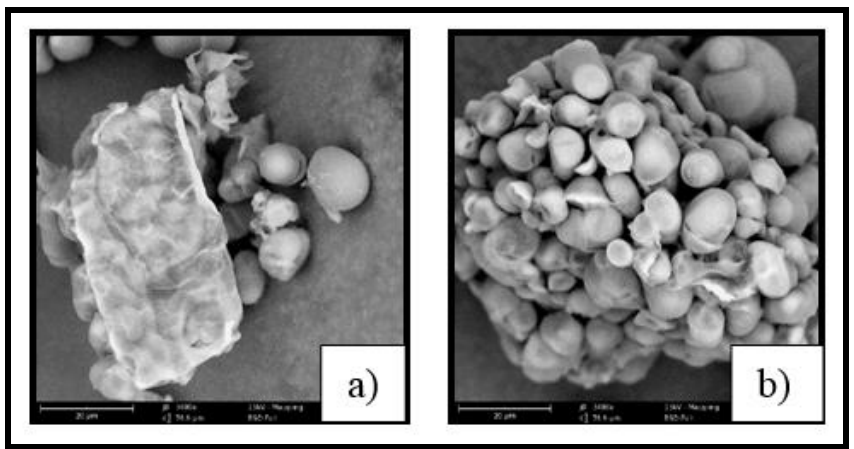

Tabela 2 - Análise elementar da farinha pura e do amido extraído do mesocarpo do babaçu

\begin{tabular}{|c|c|c|c|}
\hline \multirow{2}{*}{ Amostra } & \multicolumn{3}{|c|}{ Constituinte (\% em massa) / (\% de certeza) } \\
\cline { 2 - 4 } & $\mathrm{C}$ & $\mathrm{O}$ & $\mathrm{Na}$ \\
\hline Farinha pura & $(30,05) /(99,30)$ & $(69,95) /(98,80)$ & - \\
\hline Amido extraído & $(29,80) /(99,20)$ & $(65,97) /(98,77)$ & $(2,73) /(96,90)$ \\
\hline
\end{tabular}

Observa-se a presença de sódio na amostra do amido extraído, evidenciando que o $\mathrm{NaOH}$ não foi completamente retirado durante a lavagem. Observa-se, também, que não houve mudanças significativas na porcentagem de carbono e oxigênio na composição química das amostras, sendo que isto pode estar relacionado à presença majoritária do amido na farinha, fazendo com que as composições dos dois materiais sejam semelhantes.

\subsection{Oxidação do amido em meio ácido e básico}

A Figura 3 apresenta a análise por MEV dos produtos da oxidação ácida (a) e básica (b) do amido extraído do mesocarpo de babaçu. Observa-se, em ambas as imagens, que a maioria dos grânulos de amido permaneceram intactos. Este resultado sugere que, ou os teores de carboxila para os tratamentos ácido e básico não foram significativamente diferentes, ou talvez, o mais aceitável, que ocorreu a oxidação dos demais constituintes, como por exemplo, as impurezas proteicas. Vale ressaltar ainda que, o produto obtido pode ser chamado de amido 
branqueado, pois a modificação química consistiu, também, em uma oxidação branda de outros constituintes (Cerada, 2003).

Figura 3 - Micrografias do amido oxidado em meio ácido (a) e oxidado em meio básico (b) ampliadas 1500 vezes (aproximadamente $181 \mu \mathrm{m}$ ).

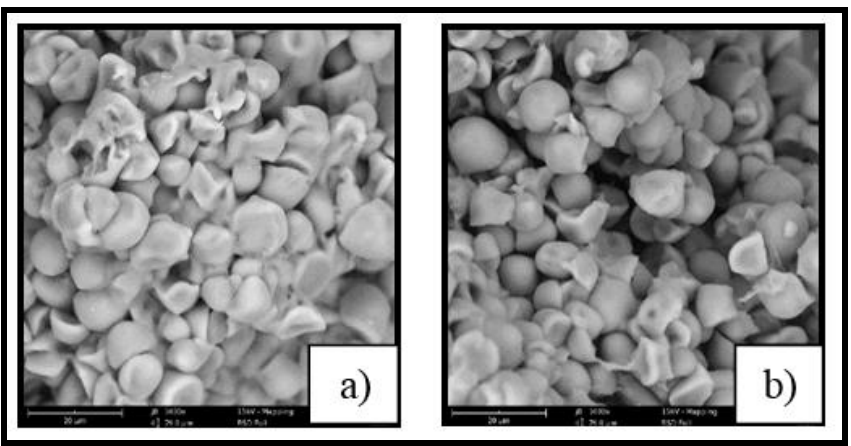

A Figura 4 apresenta os espectros de FTIR para o amido extraído e o amido oxidado em meio básico. Os resultados mostraram que houve uma pequena modificação na estrutura química do material oxidado quando comparado ao amido extraído. Observa-se dois picos de baixa intensidade (em 1419 e $1380 \mathrm{~cm}^{-1}$ ) devido ao estiramento da ligação C-O, confirmando a presença de grupos carboxílicos.

Figura 4 - Espectro FTIR para o amido extraído e oxidado em meio básico.

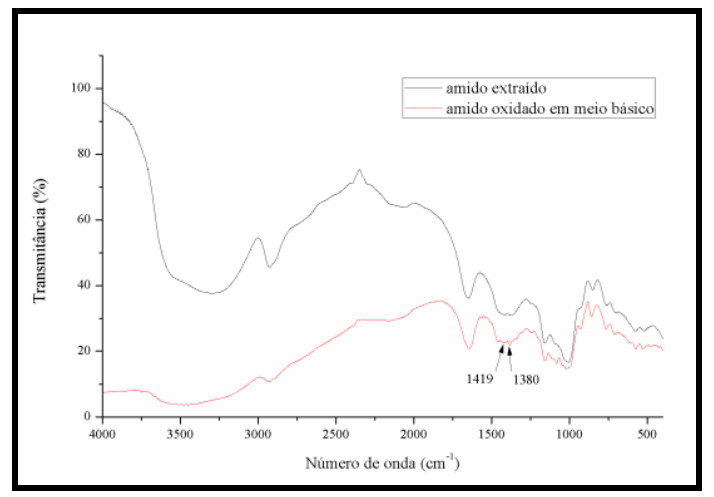

\section{CONCLUSÃO}

Com base nos resultados obtidos, conclui-se que a modificação química do amido foi branda, uma vez que sua microestrutura não apresentou alterações significativas observadas por MEV. Observou-se, também, que houve um acréscimo de apenas 3,1\% na quantidade de amido extraído em relação à farinha pura, indicando que o processo de extração não foi eficiente. Não foram observadas, também, alterações relevantes nas micrografias do amido 
oxidado em meio ácido e básico. Os espectros obtidos por FTIR mostraram bandas relacionadas com as vibrações de estiramento de ligações $\mathrm{C}-\mathrm{O}$ de grupos carboxílicos, indicando a oxidação do amido em alguma extensão. Apesar dos estudos ainda serem preliminares e considerando que o mesocarpo de babaçu é uma matéria prima rica em amido, o qual apresenta um grande potencial de exploração para aplicações tecnológicas, como por exemplo, a obtenção de bioplásticos.

\section{REFERÊNCIAS}

DIAS, A. R. G. Efeito de oxidantes, de ácidos orgânicos e da fração solúvel em água na propriedade de expansão do amido de mandioca fermentado. 2001. 166 f. Tese (Doutor em Tecnologia de Alimentos) - Faculdade de Engenharia de Alimentos, Universidade Estadual de Campinas, Campinas, 2001.

SILVA, A. P. S. Caracterização físico-química e toxicológica do pó de mesocarpo do babaçu (Orbignya phalerata Mart): subsídio para o desenvolvimento de produtos. 2011. $119 \mathrm{f}$. Dissertação (Mestrado em Ciências Farmacêuticas) - Programa de Pós-graduação em Ciências Farmacêuticas, Universidade Federal do Piauí, Teresina, 2011.

CEREDA, M. P. VILPOUX, O. DEMIATE, I. M. Amidos modificados. In: Culturas de tuberosas amiláceas latino americanas. São Paulo: Fundação Cargill, v. 3, p. 246-332, 2003.

INSTITUTO ADOLFO LUTZ. Normas Analíticas do Instituto Adolfo Lutz. Métodos Químicos e Físicos para Análise de Alimentos. $4^{\text {a }}$ ed. São Paulo: IAL, 2008, 1020 p. 